\title{
Electronic patient record development in Norway: The case for an evolutionary strategy
}

\author{
Gunnar Ellingsen ${ }^{\mathrm{a}, *}$, Eric Monteiro ${ }^{\mathrm{b}}$
}

\begin{abstract}
${ }^{a}$ Department of Clinical Medicine, Telemedicine and e-Health Research Group, University of Tromsø, 9037 Tromsø, Norway ${ }^{\mathrm{b}}$ Department of Computer and Information Science, Norwegian University of Science and Technology, Trondheim, Norway Available online 11 February 2012
\end{abstract}

\begin{abstract}
With the failure of many large-scale "big-bang" projects, combined with the lack of influence associated with many small-scale projects, we need to look for alternative strategies for implementing ICT in healthcare. One such strategy is to focus on the processes that enable successful scaling of locally developed ICT systems and how these gain a foothold in a larger market. In this paper, we contribute with empirical insight into one such scaling process. We illustrate how scale is both connected to a vendor's strategy of maintaining close user contact and influenced by how the authorities choose to organize the healthcare system. Empirically, the study draws on the establishment and growth of the Norwegian company DIPS ASA over a period of nearly 25 years, which today claims the lion's share of the electronic patient records market in Norwegian hospitals.
\end{abstract}

(c) 2012 Fellowship of Postgraduate Medicine. Published by Elsevier Ltd. All rights reserved.

\section{Introduction}

Reports on failed large-scale ICT projects in healthcare are too common for comfort [1-3]. Many question the level of ambition, the approach, and the method of ensuring wellfunctioning innovative ICT support for the delivery of health services across the different domains in healthcare. In contrast, many studies have promoted small-scale ICT systems in close collaboration with the users - frequently framed as user-led innovation [4] - as a way forward, with careful tailoring of the systems to the users' practice. Still, starting out with local ICT projects may lead to being trapped in "islands" of incompatible, local solutions.

Targeting "small" or "big" systems is not inherently good or bad. While we are sympathetic to the need for closeness to users in ICT development, we also recognize the need for

\footnotetext{
*Corresponding author. Tel.: +47 76166074.

E-mail address: gunnar.ellingsen@hn-ikt.no (G. Ellingsen).
}

health authorities and vendors to aim for innovations that have greater impact on the healthcare system [5]. However, with the failure of large "big-bang" projects, we need to pursue other strategies. One such strategy is to focus on the processes that enable successful scaling of locally developed ICT systems and how these gain a foothold in a larger market [6]. This may prove crucial for how to approach healthcare-based ICT implementations in the future. Accordingly, in this paper we contribute with empirical insight into one such scaling process. We illustrate how scale is both associated with a vendor's need to maintain close user contact and influenced by how the authorities choose to organize the healthcare system. Specifically, we address the following research questions: What characterizes the scaling of ICT systems in healthcare? How can small vendors manage the scaling processes? How is the user role transformed? What challenges lie ahead and how can these be managed?

Empirically, the study draws on the establishment and growth of the Norwegian company DIPS ASA over a period of nearly 25 years. Today the company claims the lion's share 
of the electronic patient records (EPR) market in Norwegian hospitals, and today it is on the threshold of moving into the international healthcare market. Hence DIPS ASA provides an excellent case for exploring how a user-led ICT innovation emerges and scales from within a Norwegian hospital to serving a significant part of the national market.

\section{The current state of large-scale ICT projects in Western healthcare}

In recent year, the western world has pledged substantial levels of financial investment for ICT in health care [7]. The National Programme for IT in the UK National Health Service (NHS), led by the agency NHS Connecting for Health, was estimated to cost Ė12.8 bn, although it has currently been terminated by the coalition government. In the US, the Obama administration has committed a US\$38 billion for eHealth investment [8].

A serious concern is that healthcare has been, and still is, organized according to principles of regional distribution, division of labour between specialized and more general care and combining a mix of public and private healthcare providers (albeit in different ways). Western healthcare sectors would typically be distributed across several institutional boundaries that involve general practitioners, hospitals, nursing homes, and home care services. Ensuring a cost-efficient, innovative and high-quality sector is a massive challenge in both developed and developing countries [9-11]. This motivates a series of initiatives aimed at more "integrated care". For instance, in the UK's National Health Service it is argued that:

"Current healthcare policy initiatives in the UK make significant claims about the desirability of integrated services for better healthcare, i.e. more patient-centred healthcare delivery, improved resource utilization and better management of information" [12].

Accordingly, a key goal of the "NHS Connecting for Health" programme has been to create an integrated electronic patient record linking more than 30,000 GPs to nearly 300 hospitals by 2014 [13]. No wonder, then, that the integration of healthcare software systems has remained one of the most prominent issues in healthcare software development [14]. However, despite huge technical growth in recent decades, healthcare is still a late adopter of integrated systems $[15,16]$. So far, considerable concerns have been raised about the NHS case and the ambition level has been reduced significantly [1]. Key problems appear to be related to the practical issues of integrating the vast number of systems $[16,17]$. This is not unique to the UK. In Scandinavia one can find similar examples: After major delays, the portal system project at the Oslo University Hospital turned out to be a resounding failure. After being terminated in May 2011, the project had wasted approximately EUR 23 million [18], which is probably just the tip of the iceberg. This illustrates the difficulties of establishing large-scale integrated systems. Ham et al. even claim that an "integrated electronic medical record remains an aspiration rather than a reality" [19], echoing [20], who points out that fully integrated systems in healthcare are hard to find.
An essential problem of large-scale projects is that the gap between vendors and users becomes huge; at the same time, many powerful stakeholders with contrasting interests are in play [21]. This is definitely far away from the acclaimed perspective of user-led innovation [4]. Here, we pursue a different strategy where we explore how small systems, carefully designed for one local context, can be scaled to become useful in a broader context. Pollock and Williams [6] have analysed how ERP systems are implemented in many organizations worldwide, and suggest that we should focus on how these systems are made "general". They introduce the notion of generification, which is "the supplier strategy of taking a technology that has worked in one place and attempting to make it work elsewhere, and, in principle, everywhere". While we have great sympathy for this perspective, our study differs in one principal way. Pollock and William's account of generification focuses on the implementation and adaptation of large-scale ERP packages. Often vendors of such packages attempt "to avoid getting too close to a specific local context" [22], and this limits the potential for adaptation. In comparison, the product developed in our case is developed from small-scale settings, and later targets a larger one.

\section{Method}

The study is based on an interpretative research tradition $[23,24]$ where reality is socially constructed among the participants. Our study is largely set in an ethnographic tradition, which is a useful method to gather an in-depth understanding of the people, the organization, and the broader context of their work $[23,25,26]$. Data gathering consisted of participant observations (work settings and project meetings), interviews, document analysis, and informal discussions and took place over the last decade. The two researchers have been deeply involved in studying the implementation ICT in healthcare in general and EPRs in particular for the last 15 years. They have engaged in debates on various levels; with users, vendors and policy makers. In total, they have conducted approximately 60 interviews in this period. Participant observations have been conducted in reiterated periods in six large university hospitals. They have had access to policy documents from the regional health authorities, the hospitals and vendors.

The analysis of the data is based on a hermeneutic approach where a complex whole is understood "from preconceptions about the meanings of its parts and their interrelationships" [23]. This implies that the different sources of field data were all taken into consideration in the interpretation process. The method included relatively detailed case write-ups for the sites (hospitals and vendors) involved [27] followed by an examination of the data for potential analytical themes. Patterns emerging from the data [28] were categorized by theme in an effort to develop good overviews based on the perspectives chosen.

\section{The Norwegian healthcare context}

Effective use of ICT has been the subject of a series of governmentally sponsored policy documents with corresponding change efforts spanning more than two decades 
[29-32]. While these policies have had a changing focus, a recurring theme has been the promotion of electronic patient record systems (EPRs). While it has been relatively easy for general practitioners in the community health service to implement working EPRs, the path to success has been much thornier in hospitals, particularly larger ones. As a result, implementing EPRs in Norwegian hospitals has emerged as a prolonged process from the 1990s onwards. The Norwegian hospital-based EPR market is relatively small. It was initially covered by three vendors in 2001 [33]; currently only two vendors are left, namely DIPS ASA and Siemens Medical, which offer the EPRs DIPS and Doculive, respectively. Today, DIPS ASA has $73 \%$ of the hospital-based EPR market in Norway relative to the number of institutions that run the DIPS portfolio. This includes 57,000 users of EPR/PAS.

However, these initiatives were not sufficient to achieve integrated and consistent healthcare. Accordingly, a sweeping health reform in 2002 shifted the ownership of the Norwegian hospitals from the counties to the government in an attempt to curb expenditures and poor exploitation of existing resources. Five regional health authorities with substantial autonomy replaced the former five health regions (two of the health authorities were later combined into one). Each of the regional health authorities comprised one of the former university hospitals and several local hospitals. As a result, the regional health authorities have increasingly coordinated the acquisition of ICT systems through large-scale bids for tenders. In addition, the new healthcare reform [32] will enter into force from 2012. The goal is improved integration of healthcare services between hospitals and primary care. This has made it imperative for hospital-based EPRs to be integrated with EPR systems in different institutions in the primary care sector.

\section{Case}

In this section, we take a longitudinal perspective, outlining the initiation and growth of the DIPS portfolio and the company DIPS ASA in Norwegian hospitals.

\section{Phase 1: Symbiotic EPR development with the users (1987-1997)}

With 155 employees, DIPS ASA is today a leading vendor of EPRs to Norwegian hospitals. The company has signed agreements with three out of four regional health authorities, the exception being the Central Norway Regional Health Authority. The company is headquartered in the relatively small north Norwegian city of Bodø, but has local branches in Trondheim, Førde and Tromsø as well as in the capital, Oslo. In 2010, the company's revenue totalled EUR 28 million.

The inspiration and motivation to develop an EPR system emerged in the mid-1980s from the local needs of a group of laboratory technicians at the Bodø central hospital. With interest in and knowledge of ICT systems, they had the idea of designing an EPR system for supporting the internal work processes. The rationale for this was that they had experienced first-hand how inadequately the hospital was organized (similar to other hospitals). A typical situation was that nurses who started at 5 a.m. frequently had to go back and forth between the laboratory and the wards to order laboratory tests and to collect test results. Based on these early frustrations combined with interest and knowledge of ICT systems, this small group of hospital employees was inspired to develop a patient administrative system (PAS) as a strategy for improving the situation. They were encouraged to try something themselves as they already had some experience from 1983 to 1986 with the development tool Dataflex. In addition, they saw the emergence of the network-based operating system Novell, which made it possible to connect personal computers (PCs) in a local area network for file sharing.

This was a move away from the mainframe world and into the distributed way of dealing with the challenges. Out of this, the name DIPS originated, which is an acronym for "Distributed Information as a Patient Data System". After some effort, the team was able to put the first version into use at the hospital in 1987. This was not without warnings, as the CEO of DIPS ASA recalls. He was one of the laboratory technicians participating in the start-up:

We got a lot of protests and had to fight a lot with many others who thought it was madness. Maybe it was, but the concept was really very good: cheap computers in a simple network (...) and we could offer each of the users their own computer ... that was big ... you could do whatever you wanted and the world was at your feet (CEO)

The small-scale start-up was relatively successful. During the following years, several smaller hospitals became interested. "Suddenly we had around 20 customers [smaller hospitals] in Norway on DIPS patient systems," the CEO explains.

The laboratory (LAB) and radiology module (RIS) emerged a little later, followed by the EPR module, which enabled the staff to write clinical documents related to patients. Gradually the different modules became part of a tightly integrated DIPS portfolio comprising EPR, PAS, RIS and laboratory modules. For a decade (1987-1997), the DIPS development team was part of each hospital, where the costs and the revenues were divided between the hospitals involved. In principle the hospitals obtained the system free of charge, but they contributed to funding of the employed developers and other common expenses.

\section{Phase 2: Successful uptake with smaller hospitals (1997-2004)}

In 1997, DIPS ASA was established as a limited company with eight employees. The majority of shares were held by the employees. This ensured a strong commitment to the developed ICT portfolio among the employees. During this period, the DIPS portfolio was successfully put into use among smaller regional hospitals. In 2001, 23 hospitals (with 2336 beds in total) had implemented DIPS [33]. Although rich functionality existed in the EPR, it was basically used in line with the other Norwegian EPRs for entering and reading clinical data [33].

However, the core strength of the DIPS portfolio regarding functionality was that it contained the modules PAS, LAB, 
EPR and RIS, which was ideal for local and medium-sized hospitals. In this way, DIPS ASA could promote its portfolio as a complete and integrated solution based on "common architecture, integrated modules and a common logon procedure across the different modules". Moreover, to promote integration, DIPS ASA developed an API (Application Program Interface) enabling integration with systems developed by other vendors.

A key concern for DIPS ASA in this process was to maintain close contact with its customer base in the various hospitals-i.e. to pay attention to its historical commitment to user-led development. Accordingly, a core strategy was to recruit new employees from the various implementation projects at the hospitals as a way of maintaining robust connections with the different hospitals. In this way, DIPS ASA managed to keep up a stable workforce as well as maintenance of its fundamental vision of close user contact.

The vendor therefore made a considerable effort to respond quickly to user requests and to fix technical problems experienced by the users. Through its success, the vendor had developed a considerable portfolio, built on the database platform Btrieve and the development tool Dataflex, which was running in a MS-DOS-based environment. This had to be changed to a more modern technology, namely an Oracle database, the development tool Delphi and a Windows platform. This process started in the mid1990s. By Easter 1999, the first hospital was up and running with the new version. The migration process was extremely challenging, but through the existing connections to the hospitals, DIPS ASA managed to complete it:

I believe what saved us in this period was our cultural heritage of coming from a hospital. We manage to identify ourselves with the customers and that creates mutual trust (...) So, even if we struggled insanely in 1999 to make DIPS work, we managed to get the systems up and running (CEO).

In this period (2000-2002), the internal organization in DIPS ASA was transformed. Originally, small development teams consisting of 2-3 persons had controlled different parts of the DIPS portfolio. The advantage of this was these teams could focus on the goals and the functionality they were developing. The small size of the teams ensured very close contact with the users. However, this way of organizing the development activities increasingly became a problem in terms of internal coordination and prioritization of the activities. The teams became too autonomous, as they frequently acted on direct commissions from the customers. This was a big drawback for the company, because it scaled badly. The solution was to establish a form of matrix organization with a mix of development projects and traditional project management, which became the most important tool for the coming years.

\section{Phase 3: Targeting the larger hospitals - integration and refactorization (2004 onwards)}

The establishment of the regional health authorities in 2002 fundamentally changed the relationship between users, customers and vendors. The regional health authorities increasingly undertook the responsibility of coordinating the acquisition of new systems to the hospitals through largescale bid-for-tender processes. A consequence was that DIPS ASA had to refocus its strategy from smaller hospitals to the regional health authorities, including the large-scale university hospitals in Norway. This had direct consequences for the close vendor/user relationship between DIPS ASA and its users. The CEO explains:

"We talk to both users and customers, of course. However, there is a huge difference between these two. While the users are important to us, it is the customers that decide; they buy the DIPS portfolio from us, they sign the contracts and promote requests for changes. Hence our relationship with the customers is extremely important $(\ldots)$ the users have to pass through some regimes to exercise this kind of influence"

In particular, these changes are expressed through the promotion of standardization of the ICT portfolios in each of the healthcare domains. In the last large-scale ICT bid for tender in Norway, finalized by the Northern Norway Regional Health Authority in 2011, it was stated that:

The acquisition of a standardized ICT portfolio for the entire health region will contribute to more unity in the patient treatment, more user friendliness and more efficient systems management and operation of the ICT portfolio in the health region (Advisor, Northern Norway Regional Health Authority)

This implied that the different hospitals in one health region are basically required to run the same application for particular domains, such as EPRs, LAB, RIS and PAS.

Moving into the markets of university hospitals triggered new demands for specialized functionality. Here, it has been difficult for DIPS ASA to respond adequately to the demands from all these different domains. For instance, while the LAB module was initially expected to cover the needs of several of the laboratories in a hospital, more specialized functionality is needed for the laboratories in the university hospitals, which have resulted in many different kinds of laboratory systems. The consequence is that the core functionality offered by DIPS ASA for the Norwegian University hospital market is PAS/EPR, while the whole package of EPR/PAS/RIS/LAB is still offered for the smaller hospital market.

To face these challenges, DIPS ASA has initiated a process of restructuring its ICT portfolio. From tightly integrated modules - in reality a great deal of functionality in one large chunk of software - DIPS ASA has put considerable effort since 2006 into splitting up the product portfolio into several autonomous/modularized products through a service-oriented architecture, which is intended to support integration between systems from different vendors and technologies as well as to prepare the DIPS portfolio for the international market. An essential part of this involved moving the old portfolio to a new service-oriented architecture called DINA. This has in itself proven to be a very slow and cumbersome process.

However, the university hospitals have also demanded more support for their internal work processes and patient pathways through the EPR. The reason is that traditionally EPRs in health care have primarily played the role of an 
"off-line" tool for documentation of treatment, results and clinical assessments where patients' interactions with the different parts of a health facility are documented - after the interactions have taken place. Increasingly there are demands for EPRs as an "online" operational tool for support of work processes [34] where the EPR is intended to trigger the interactions of health staff and patients while they are happening.

The vendor strategy has been to start a redesign process of its software, making it more configurable for domain experts. Then it is possible to adapt the functionality of the EPR for the support of work processes and for tailoring support for patient pathways for a range of different diagnoses or conditions. For example, for a given diagnosis, the EPR will instruct health staff about when to admit a patient, when to take blood specimens and X-rays, when to admit the patient for surgery and what to do after surgery. Basically, it outlines a well-structured plan for the stay in the hospital. To accomplish this, it is essential to introduce more structure to the EPR content. A strategy here has been to implement OpenEHR archetypes [35], making it possible to define the content in the EPR in a dynamic way. Internally, DIPS ASA has implemented yet another organizational structure, where the development work is organized according to SCRUM team [36]. A goal of this has been to ensure more autonomy and productivity in the teams.

\section{Conclusion}

A key condition for scaling and generification [6] in the healthcare market appears to be DIPS ASA's capability and willingness for transformation, for adapting to both users' and health authorities' increasing requirements. It is evident that the technology, the internal organization and the relationship to the users/customers have undergone huge changes during the last 25 years. In a technical sense, it started out with Dataflex and PCs in a network, but has now transformed into domain-configurable software and structured content in the form of archetypes. In this sense, the company has managed to respond to increasing and new demands in the healthcare market. The company has also managed to offer something "additional" beyond straightforward ICT support, which in the first phase gave the users a $P C$ for various type of use, and in the second phase offered a completely integrated package of EPR, PAS, LAB and RIS. Currently, the aim is now to offer a high degree of useradaptable software. Still, the success of DIPS to date is no guarantee for future success. The scaling in scope and market share as well as new demands from (regional/ national) health authorities and the company's increasing customer base present DIPS ASA with immediate challenges. It is therefore evident that extremely difficult challenges lie ahead. Methods, strategies and technology need to evolve in tandem with an evolving health care sector's demands. We discuss salient concerns.

Firstly, over the years DIPS ASA has invested substantial effort in a close dialogue with users in the hospitals and the user-led innovation [4] has been a foundation for the growth of DIPS ASA. However, this close relationship has become increasingly difficult to sustain as DIPS ASA has acquired larger market shares, particularly including the larger university hospitals. In addition, the procurement of ICT in the hospitals is no longer carried out between vendors and hospitals. Instead, these processes are coordinated through tender processes between ICT vendors and regional health authorities, making the distance between the vendors and users much larger. Many of the bid-for-tender documents have been "copied from region to region" as one centrally placed ICT consultant expressed it, illustrating a trend of decreasing user involvement. This tendency has been even more expressed as users typically have been granted only a $43 \%$ influence for specific user demands; other domains such as the technical infrastructure and business domains inevitably need to have an increasing say due to the larger scope of ICT projects.

Secondly, the modules in the DIPS portfolio are tightly integrated with each other. This has traditionally been seen as an advantage in terms of usability as the different modules interact seamlessly. The technical environment has constituted the same technical platform where the vendor has had complete control of the involved components and their mutual interactions. Recently this situation has changed completely as DIPS ASA's core modules in the university hospitals represent only half of the package, namely PAS/EPRs. As a result, improved integration between systems inside the hospitals as well as outside [32] is an increasing demand. Accordingly, the traditional advantages of the DIPS package solution now become the core challenge, hence accounting for the vendor's effort to defactorize the DIPS portfolio. Accomplishing large-scale integration for inter-organizational work process support is of course much harder than simply offering other ICT companies integration interfaces to the DIPS portfolio. This illustrates that it is difficult to scale in real life, as many of the problems seen in many other large-scale ICT projects are increasingly faced by DIPS ASA.

Thirdly, the scaling of the healthcare market, the increasing specialization (i.e. EPR/PAS) in the various health care domains, and the modularization of the DIPS portfolio appear to have two consequences in terms of market positions. One is the international potential of a specialized product that is easy to integrate in a larger portfolio. On the other hand, the very same process makes the company more exposed to international competition within the corresponding market segments. The healthcare market is increasingly internationalized with much fiercer competition. There is growing competition from international players (iMDsoft, Philips, and others) in the Norwegian market. An illustration is that several providers of electronic medical charts (i.e. a core function in all EPRs, but still not implemented) are now ready to deliver systems to the Norwegian market. This may easily turn into a self-reinforcing process where the demands for specialization and integration presuppose even more scaling to remain in a competitive position.

In summary, it is clear that generification processes do not occur in a vacuum. Technologies, practices, processes and authorities strategies increasingly become intertwined, accounting for increasing interdependencies [37] and future risk [2]. This also recognized by DIPS ASA's CEO when he points out what lies ahead.

"The strategic international focus, the new architecture and the refactorization occur as a tightly interwoven 
process. It is a huge project, but we have to succeed very much of our future depends on that".

Building on the findings in this paper, future work may focus on the generification and transformation processes. In line with investigating how the relationship between users and vendors is transformed in historic scaling processes, we may also examine what constitutes users, customers and vendors in different phases of large-scale ICT acquisitions processes.

\section{References}

[1] Curtis P. Government urged to abandon NHS IT programme [Internet]. guardian.co.uk.; 2011 [cited 2011 November 10]. Available from: 〈http://www.guardian.co.uk/society/2011/ may/18/government-urged-to-abandon-nhs-it-programme $\rangle$.

[2] Hanseth Ole, Ciborra C. Risk, complexity and ICT. Illustrate. Edward Elgar Publishing Ltd.; 2007.

[3] Heeks R. Health information systems: failure, success and improvisation. International Journal of Medical Informatics 2006;75(2):125-37.

[4] von Hippel E. Lead users: an important source of novel product concepts. Management Science 1986;32(7):791-805.

[5] Coiera E. Building a National Health IT System from the middle out. Journal of the American Medical Informatics Association: JAMIA 2009;16(3):271-3.

[6] Pollock Neil, Williams R. Software and organisations. The biography of the enterprise-wide system or how SAP conquered the world. Routledge Studies in Technology, Work and Organizations; 2009.

[7] Chiasson M, Reddy M, Kaplan B, Davidson E. Expanding multidisciplinary approaches to healthcare information technologies: what does information systems offer medical informatics? International Journal of Medical Informatics 2007;76(Suppl. 1):76S.

[8] Black AD, Car J, Pagliari C, Anandan C, Cresswell K, Bokun T, et al. The impact of eHealth on the quality and safety of health care: a systematic overview. PLoS Medicine 2011;8(1): e1000387.

[9] Burns LR, Muller RW. Hospital-physician collaboration: landscape of economic integration and impact on clinical integration. The Milbank Quarterly 2008;86(3):375-434.

[10] Kohn LT, Corrigan J, Donaldson MS, editors. To err is human. Building a safer health system. National Academies Press; 2000.

[11] Light $D$. The sociological character of health-care markets. In: Albrecht GL, Fitspatrick R, Scrimshaw SC, editors. The handbook of social studies of health and medicine. London: Sage Publications; 2000. p. 394-408.

[12] Martin D, Mariani J, Rouncefield M. Managing integration work in an NHS electronic patient record (EPR) project. Health Informatics Journal 2007;13(1):47-56.

[13] BBC NEWS. Services back after NHS IT crash; 2006, 〈http:// news.bbc.co.uk/2/hi/health/5233604.stm $>$.

[14] Mykkanen J. A process for specifying integration for multi-tier applications in healthcare. International Journal of Medical Informatics 2003;70(2-3):173-82.

[15] Auditor General. Riksrevisjonens undersøkelse om IKT i sykehus og elektronisk samhandling i helsetjenesten [The Office of the Auditor General of Norway's evaluation on ICT in hospitals and electronic interaction in the health service]. Document no. 3:7 (2007-2008). Oslo: 2008.
[16] Cross M. Information technology Will Connecting for Health deliver its promises? British Medical Journal 2006;332:599-601.

[17] Car J, Black A, Anandan C, Cresswell K, Pagliari C, McKinstry B, et al. The impact of eHealth on the quality and safety of healthcare: a systematic overview \& synthesis of the literature. Springer; 2008.

[18] Lyse MI. Stopper it-prosjekt til 160 millioner [Terminates 21 million EUR ICT project] [Internet]. Computerworld; 2011 [cited 2011 November 10]. Available from: 〈http://www.idg. no/computerworld/article207882.ece $>$.

[19] Ham C, Dixon J, Chantler C. Clinically integrated systems: the future of NHS reform in England? British Medical Journal 2011; 342: d905.

[20] Berg M. Medical work and the computer-based patient record: a sociological perspective. Methods of Information in Medicine 1998;37(3):294-301.

[21] Larsen E, Ellingsen G. Facing the Lernaean Hydra: the nature of large-scale integration projects in healthcare. In: Kautz $\mathrm{K}$, Nielsen PA, editors. Lecture notes in business information processing; 2010. p. 93-110.

[22] Wang M. Cultivating the "Generic Solution"- the emergence of a chinese Product Data Management (PDM) Software Package; 2007.

[23] Klein HK, Myers MD. A set of principles for conducting and evaluating interpretive field studies in information systems. MIS Quarterly 1999;23(1):67.

[24] Walsham G. Interpretive case studies in IS research: nature and method. European Journal of Information Systems 1995;4(2): 74-81.

[25] Harper RHR. The organisation in ethnography. Computer Supported Cooperative Work (CSCW) 2000:239-64.

[26] Forsythe DE. "It's just a matter of Common Sense": ethnography as invisible work. Computer Supported Cooperative Work (CSCW) 1999:127-45.

[27] Eisenhardt KM. Building theories from case study research. Academy of Management Review 1989;14(4):532-50.

[28] Schultze UA. Confessional account of an ethnography about knowledge work. MIS Quarterly 2000;24(1):3.

[29] HOD. More Health for Each bIT: information technology as a means for an improved health service. Action plan 1997-2000. Ministry of Health and Social Affairs; 1996.

[30] HOD. Governmental action programme 2001-2003. Electronic interaction in the health and social sector "say @"; 2001.

[31] HOD. Te@mwork 2007: Electronic Cooperation in the Health and Social Sector. National strategy 2004-2007 for Norway; 2004.

[32] HOD. Helse-og omsorgsdepartementet: Samspill 2.0. Nasjonal strategi for elektronisk samhandling i helse-og omsorgssektoren. Olso: 2008.

[33] Lærum Hallvard, Ellingsen G, Faxvaag A. Doctors' use of electronic medical records systems in hospitals: cross sectional survey. British Medical Journal 2001;323:1344-9.

[34] National_ICT. De regionale helseforetakenes felles IKT-strategi [the regional health authorities' common ICT strategy] 2010 $2011 ; 2010$.

[35] OpenEHR. openEHR [Internet]; 2011 [cited 2011 November 15]. Available from: 〈http://www.openehr.org/home.html >.

[36] Johannessen LK, Ellingsen G. Integration and generificationAgile Software Development in the healthcare market. Computer Supported Cooperative Work (CSCW) 2009;18(5-6):607-34.

[37] Perrow C. Normal accidents: living with high-risk technologies. New York: Basic Books; 1984. 